\title{
Assessment of Quality of Life in Egyptian Children after Cochlear Implant
}

\author{
Original Ebtessam Hamed Nada', Shaima Mohamed Serag Eldin'2, Ibrahim Kabbash \\ Article Mahmoud Fawzy Mandour ${ }^{4}$, Amani Mohamed El-Gharib ${ }^{5}$ \\ ${ }^{1}$ Department of ENT, Faculty of Medicine, Zagazig University, ${ }^{2,4,5}$ Department of ENT, \\ ${ }^{3}$ Public Health and Community Medicine, Faculty of Medicine, Tanta University, Egypt.
}

\begin{abstract}
Introduction: Cochlear implantation (CI) is gradually growing in Arabic countries and there have only been a few studies about the quality of life (QL) of pediatric patients in this area.

Objective: To investigate various aspects of QL in CI pediatric patients using a Parents' Perspective Questionnaire and to evaluate the significance of such aspects.

Patients and Methods: This was a prospective cohort study carried out on a $71 \mathrm{CI}$ pediatric patients. Their age ranged from 4-18 years. Parents were asked to answer the Parents' Perspective Questionnaire. This questionnaire was designed with 11 subscales and 58 questions in total. All questions were scaled from 1 to 5: (1 strongly agree; 2 agree; 3 neither agree nor disagree; 4 disagree; and 5 strongly disagree).

Results: Children implanted at age $\geq 4$ year, had better score regarding positive effect of implant, communication, selfconfidence and services of implant centers. Similar significant better scores were observed with advance of age of the children. However, younger implanted children had better score regarding communication.

Conclusion: CI has positive effect on the quality of life. Patients' satisfaction is correlated with age of implantation and duration of the implant use.
\end{abstract}

Key Words: Children quality of life, Cochlear implant, health related quality of life, quality of life, sensorineural hearing loss.

Received: 11 March 2020, Accepted: 16 July 2021

Corresponding Author: Ebtessam Hamed Nada, MD, Department of ENT, Faculty of Medicine, Zagazig University, Egypt, Tel.: 01227752699, E-mail: e_hossam1999@yahoo.com

ISSN: 2090-0740, 2021

\section{INTRODUCTION}

Children with severe and/or profound hearing loss (HL) are reported to substantially get benefit from using a cochlear implant $(\mathrm{CI})$, alongside with proper auditory rehabilitation $^{[1]}$. These children have greater likelihood of acquiring oral language, integrated in regular schools and participating in social activities ${ }^{[2,3]}$. Majority of studies evaluating CI outcomes has been concerned with the auditory, language and speech performance, and costeffectiveness analysis ${ }^{[1,3-4]}$. So, there is an increasing interest in complementary studies about the quality of life in pediatric cochlear implant users. Quality of life is defined as one's perception of their position in life in the context of the culture and value systems in which they live and in relation to his goals, expectations, standards, and concerns ${ }^{[5]}$. For a specific group of people "as group of parents of CI children" health related quality of life (HRQOL) can be defined as groups' perceived physical and mental health which represents a broad concept of social functioning and well-being of their implanted children that includes both positive and negative aspects of their new life. ${ }^{[6]}$
The challenge is in putting a group of parameters within a comprehensive form to evaluate physical, mental and social aspects that are important for the child. Also, how such aspects may progress during his/her development are determining factors in this type of assessment. So, the aim of this work was to investigate various aspects of QL in CI pediatric patients using a Parents' Perspective Questionnaire and to evaluate the significance of such aspects.

\section{PATIENTS AND METHODS:}

This was a prospective cohort study carried out on a number of CI pediatric patients who attended audiology unit and phoniatric unit at Tanta University and Zagazig University, for regular follow-up and rehabilitation, during period between February and October 2019.

The study was performed after approval from the local ethics committee of Zagazig University, Egypt. Parents were informed about the study and approved the study. 
All children had prelingual hearing loss with normal psychiatric and neurologic status and normal radiologic findings. The age range of children was 4-18 years ( $7 \pm 4.3$ years). Minimum time period for subject inclusion was 6 month of regular use of the device with time range of 6 months -6 years of regular use $(3.1 \pm 1.8$ years). Patients with irregular device use, implantation less than 6 months, or those who refused to participate were excluded from the study.

A total of 153 parents were asked to reply to our questionnaire, but only 71 patients who completed the questionnaire have been included in our study. There were 29 patients younger than 5 years old and 42 patients older than 5 years old ( 38 male and 33 female). Age at time of implantation was less than 4 years old in 35 patients and at 4 years old or older in 36 patients. Time since implantation was less than 18 months for 48 patients, whereas this was more than 18 months in 23 patients.

Parents were asked to answer the Parents' perspective Questionnaire which was translated into the Arabic language with proven reliability ${ }^{[5,6]}$. This questionnaire was designed with 11 subscales and 58 questions in total. All questions were scaled from 1 to 5: (1 strongly agree; 2 agree; 3 neither agree nor disagree; 4 disagree; and 5 strongly disagree). Missing answers were scored as 0 . Also, the validity of the questionnaire was supported by the use of negative questions (Appendix A).

- All children's parents were thoroughly counseled about the procedure, stating the values, the hazards, and the aim of the study.

- Written consent was obtained and signed by each participant.

- Any unexpected complication that will come out during the course of the research will be cleared to the participants and to the ethical committee on time.

- Every participant will deliver a code number.

- The outcomes of the research will be applied only in scientific use.

- The participation is voluntary and that subject may discontinue participation at any time without penalty or loss of benefits.

\section{Statistical Analysis:}

Statistical analyses were performed using the Statistical Package for the Social Sciences (SPSS) v 20.0 software (IBM Corporation; Chicago, IL, USA). All data were tested for conformity to normal distribution. An independent samples t-test or one-way analysis of variance was performed for the analysis of normally distributed continuous variables. A Mann-Whitney U-test and a Kruskal-Wallis test were performed for the analysis of nonnormally distributed continuous variables. A chi- square test was used for the analysis of categorical variables. The results were expressed as mean \pm standard deviation, median $(\min -\max ), \mathrm{n}$, and percentage. A value of $p<0.05$ was accepted as statistically significant.

\section{RESULTS:}

A total of 153 parents were asked to reply to our questionnaire, but only 71 patients who completed the questionnaire have been included in our study. All patients have been followed up regularly for their centers with special report about their performance in the last 6 months before application of the questionnaire, and all of them used their device regularly with systematic speech therapy. There were 29 patients younger than 5 years old and 42 patients older than 5 years old ( 38 male and 33 female) at the time of testing. Age at time of implantation was less than 4 years old in 35 patients and at 4 years old or older in 36 patients. Time of implant use was less than 18 months in 48 patients, whereas this was more than 18 months in 23 patients.

Regarding the "Positive effect of implant" subscale, children implanted at age $\geq 4$ years old have reported better overall score than those implanted at younger age $(34.22+9.44 \& 41.37+10.03$ respectively, $p=0.003)$. Also, children aged $\geq 5$ years old at time of filling questionnaire have reported better overall subscale score compared to those aged $<5$ years old $(34.57+9.13 \& 42.34+10.34$ respectively, $p=0.001$ ). However, regarding the subscales of "Decision of implantation", "Process of implantation", "Support", "Wellbeing and happiness", "Social relationship", "Services at implant center" and "General" there was no statistically significant impact of neither age of the child or age at implantation nor duration of implant usage (Table 1\&2).

Similarly, children implanted at age $\geq 4$ years old have reported a statistically significant better subscale score than those implanted at younger age on the "Self-confidence" subscale $(39.44+14.54 \& 47.09+13.02$ respectively, $p=0.023)$ and on the "Service of implant center" subscale $(32.96+12.13 \& 39.05+13.40$ respectively, $p=0.049)$. On contrary, children implanted at age $\geq 4$ years old have reported a slightly worse, but statistically significant, subscale score on the "Communication" subscale $(36.56+11.83 \& 32.51+10.36, p=0.027)$ (Table 1).

Also, on the "Communication" and "Self-confidence" subscales, children aged $\geq 5$ years old at time of filling questionnaire have reported better overall subscales scores compared to those aged $<5$ years old $(36.38+11.20$, 
$40.10+14.20$ and $44.00+10.42,47.72+13.26, p=0.005$ and 0.025 , respectively). (Table 2 )

Duration of implant usage had a statistically significant impact on the "Education" subscale. Children with implant usage duration $\geq 18$ months have reported overall subscale score better than those with less duration time $(30.00+8.79 \& 36.35+1.33$ respectively, $p=0.012)$ (Table 3\& 4).

Correlation between age of the child, age at implantation and duration of CI use revealed negative significant correlation regarding positive effect of the implant and self-confidence which means the improvement of those aspects with younger age of implantation. While communication skills and education improves with time after $\mathrm{CI}$ as revealed by the negative significant correlation with duration since implantation (lower scores are better scores) (Table 6).

All subscales questions were significantly correlated to the related subscale score except for a few numbers of questions (for questions no: 6,7,19, 55 and 57, p values were $0.56,0.088,0.14,0.571$ and 0.227 respectively) (Table 7). However, all of them were significantly correlated to the total score (Table 8 \& Figure 1)

Table 1: Distribution of studied children by their characteristics

\begin{tabular}{|c|c|c|}
\hline Variables & Number $(n=71)$ & $\%$ \\
\hline \multicolumn{3}{|l|}{ Age in years: } \\
\hline$<5$ & 29 & 40.8 \\
\hline$>5$ & 42 & 59.2 \\
\hline \multicolumn{3}{|l|}{ Age at operation: } \\
\hline$<4$ & 35 & 49.3 \\
\hline $4+$ & 36 & 50.7 \\
\hline \multicolumn{3}{|l|}{ Sex: } \\
\hline Males & 38 & 53.5 \\
\hline Females & 33 & 46.5 \\
\hline \multicolumn{3}{|c|}{ Duration since implantation in months: } \\
\hline$<18$ & 48 & 67.6 \\
\hline$>18$ & 23 & 32.4 \\
\hline \multicolumn{3}{|l|}{ Number of siblings: } \\
\hline 0 & 3 & 4.2 \\
\hline 1 & 28 & 39.4 \\
\hline 2 & 28 & 39.4 \\
\hline $3+$ & 12 & 17.0 \\
\hline \multicolumn{3}{|l|}{ Fathers job: } \\
\hline Unemployed & 12 & 16.9 \\
\hline Manual worker & 25 & 35.2 \\
\hline Employee & 20 & 28.2 \\
\hline Professional & 11 & 15.5 \\
\hline Private work & 3 & 4.2 \\
\hline \multicolumn{3}{|l|}{ Mothers job: } \\
\hline Housewife & 63 & 88.7 \\
\hline Working & 8 & 11.3 \\
\hline
\end{tabular}


Table 2: Mean and standard deviation of subscale of the quality of parents' perception of the quality of life after pediatric cochlear implantation in relation to sex of children

\begin{tabular}{lcccc}
\hline Items of quality of life & Maless & Females & $\mathrm{t}$ & $p$ \\
\hline Decision for implantation & $33.23+8.97$ & $36.54+7.95$ & 1.631 & 0.107 \\
Process of implantation & $37.70+11.96$ & $38.33+10.28$ & 0.238 & 0.812 \\
Positive effect of the implant & $37.89+10.30$ & $37.58+10.49$ & 0.129 & 0.898 \\
Support & $31.16+8.22$ & $29.94+9.17$ & 0.590 & 0.557 \\
Communication & $40.32+11.21$ & $38.55+11.82$ & 0.647 & 0.520 \\
Self confidence & $43.47+14.77$ & $42.91+13.83$ & 0.165 & 0.869 \\
Wellbeing and happiness & $39.65+15.10$ & $37.58+13.31$ & 0.609 & 0.544 \\
Social relationships & $37.68+12.29$ & $39.27+12.51$ & 0.539 & 0.592 \\
Education & $34.47+11.67$ & $39.09+10.19$ & 0.146 & 0.884 \\
Services of implant center & $34.39+12.33$ & $37.78+13.79$ & 1.094 & 0.278 \\
General & $45.00+9.80$ & $44.09+11.07$ & 0.367 & 0.715 \\
Total score & $37.31+7.00$ & $37.75+7.25$ & 0.259 & 0.796 \\
\hline
\end{tabular}

Table 3: Mean and standard deviation of subscale of the quality of parents' perception of the quality of life after pediatric cochlear implantation in relation to age at operation

\begin{tabular}{lcccc}
\hline Items of quality of life & $<4$ years & $>4$ years & $\mathrm{t}$ & $p$ \\
\hline Decision for implantation & $34.61+9.27$ & $34.92+8.06$ & 0.150 & 0.881 \\
Process of implantation & $35.71+11.89$ & $40.21+10.02$ & 1.724 & 0.089 \\
Positive effect of the implant & $41.37+10.03$ & $34.22+9.44$ & 3.093 & $0.003^{*}$ \\
Support & $30.29+8.64$ & $30.89+8.74$ & 0.292 & 0.771 \\
Communication & $32.51+10.36$ & $36.56+11.83$ & 2.255 & $0.027^{*}$ \\
Self confidence & $47.09+13.02$ & $39.44+14.54$ & 2.331 & $0.023^{*}$ \\
Wellbeing and happiness & $39.81+14.86$ & $37.59+13.72$ & 0.653 & 0.516 \\
Social relationships & $39.31+12.52$ & $38.56+12.26$ & 0.598 & 0.552 \\
Education & $33.29+12.77$ & $35.28+8.86$ & 0.765 & 0.447 \\
Services of implant center & $39.05+13.40$ & $32.96+12.13$ & 2.007 & $0.049^{*}$ \\
General & $46.29+9.65$ & $42.92+10.85$ & 1.381 & 1.242 \\
Total score & $38.57+7.05$ & $36.49+7.04$ & 0.172 & 0.218 \\
\hline
\end{tabular}

*Significant

Table 4: Mean and standard deviation of subscale of the quality of parents' perception of the quality of life after pediatric cochlear implantation in relation to duration of implantation

\begin{tabular}{lcccc}
\hline Items of quality of life & $<18$ months & $>18$ months & $\mathrm{t}$ & $p$ \\
\hline Decision for implantation & $34.88+7.93$ & $34.53+10.08$ & 0.158 & 0.875 \\
Process of implantation & $38.54+11.13$ & $36.85+11.31$ & 0.597 & 0.552 \\
Positive effect of the implant & $38.08+10.37$ & $37.04+10.39$ & 0.395 & 0.694 \\
Support & $32.25+9.36$ & $29.22+6.87$ & 0.927 & 0.357 \\
Communication & $41.08+11.49$ & $36.17+10.89$ & 1.714 & 0.091 \\
Self confidence & $43.25+14.54$ & $43.13+13.91$ & 0.33 & 0.974 \\
Wellbeing and happiness & $37.22+13.46$ & $41.74+15.60$ & 1.256 & 0.213 \\
Social relationships & $39.08+13.59$ & $37.04+9.28$ & 0.650 & 0.518 \\
Education & $36.35+1.33$ & $30.00+8.79$ & 2.586 & $0.012^{*}$ \\
Services of implant center & $35.83+14.51$ & $36.23+9.55$ & 0.120 & 0.905 \\
General & $45.42+10.61$ & $42.83+9.75$ & 0.988 & 0.795 \\
Total score & $37.98+7.43$ & $36.55+6.30$ & 0.327
\end{tabular}


Table 5: Mean and standard deviation of subscale of the quality of parents' perception of the quality of life after pediatric cochlear implantation in relation to age of child

\begin{tabular}{lcccc}
\hline Items of quality of life & $<5$ years & $>5$ years & $\mathrm{t}$ & $p$ \\
\hline Decision for implantation & $36.26+8.81$ & $33.74+8.42$ & 1.213 & 0.229 \\
Process of implantation & $36.38+12.22$ & $39.11+10.33$ & 1.015 & 0.314 \\
Positive effect of the implant & $42.34+10.34$ & $34.57+9.13$ & 3.340 & $0.001^{*}$ \\
Support & $30.34+8.85$ & $30.76+8.59$ & 0.199 & 0.843 \\
Communication & $44.00+10.42$ & $36.38+11.20$ & 2.897 & $0.005^{*}$ \\
Self confidence & $47.72+13.26$ & $40.10+14.20$ & 2.285 & $0.025^{*}$ \\
Wellbeing and happiness & $39.54+13.91$ & $38.10+14.60$ & 0.418 & 0.677 \\
Social relationships & $39.86+12.30$ & $37.43+12.39$ & 0.816 & 0.418 \\
Education & $33.79+13.54$ & $34.64+8.86$ & 1.696 & 0.750 \\
Services of implant center & $39.08+14.50$ & $33.81+11.63$ & 1.105 & 0.094 \\
General & $46.21+9.97$ & $43.45+10.56$ & 1.641 & 0.273 \\
Total score & $39.16+7.12$ & $36.39+6.89$ & 0.105 \\
\hline
\end{tabular}

*Significant

Table 6: Correlation between quality of life, age, age at operation and duration since operation

\begin{tabular}{lcccccc}
\hline \multirow{2}{*}{ Quality of life } & \multicolumn{2}{c}{ Age of child } & \multicolumn{2}{c}{ Age at operation } & \multicolumn{2}{c}{ Duration since operation } \\
& $\mathrm{r}$ & $p$ & $\mathrm{r}$ & $p$ & $\mathrm{r}$ & $p$ \\
\hline Decision for implantation & -0.112 & 0.352 & -0.125 & 0.299 & 0.000 & 1.000 \\
Process of implantation & 0.126 & 0.293 & 0.172 & 0.152 & -0.035 & 0.772 \\
Positive effect of the implant & -0.322 & $0.006^{*}$ & -0.280 & $0.018^{*}$ & -0.130 & 0.280 \\
Support & 0.048 & 0.692 & 0.097 & 0.421 & -0.063 & 0.599 \\
Communication & -0.222 & 0.063 & -0.062 & 0.606 & -0.274 & $0.021^{*}$ \\
Self confidence & -0.238 & $0.046^{*}$ & -0.279 & $0.018^{*}$ & 0.015 & 0.902 \\
Wellbeing and happiness & -0.039 & 0.746 & -0.094 & 0.434 & 0.063 & 0.600 \\
Social relationships & -0.133 & 0.268 & 0.065 & 0.589 & -0.119 & 0.321 \\
Education & -0.025 & 0.837 & 0.181 & 0.130 & -0.288 & $0.015^{*}$ \\
Services of implant center & -0.180 & 0.133 & -0.215 & 0.071 & 0.021 & 0.860 \\
General & -0.231 & 0.053 & -0.165 & 0.169 & -0.134 & 0.264 \\
Total score & -0.176 & 0.142 & -0.117 & 0.329 & -0.114 & 0.342 \\
\hline
\end{tabular}

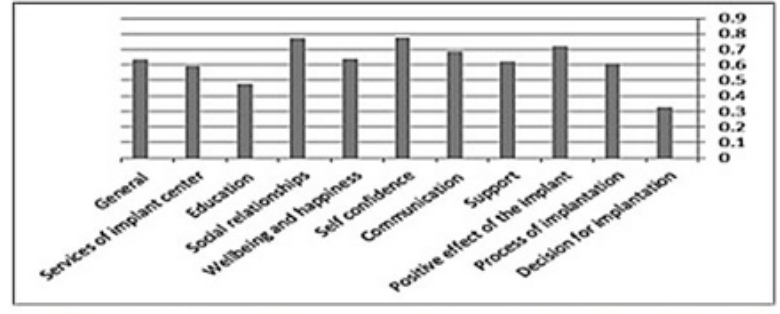

Figure (1): Subscales of the quality of parents' perception of the quality of life after pediatric cochlear implantation.

\section{DISCUSSION}

Hearing loss has its adverse effects on patients' life as regards communication, education and many other aspects. Social withdrawal, low self-esteem and unemployment are some of the drawbacks of untreated hearing loss among children ${ }^{[7]}$.
Literature is gradually getting richer in internationally published studies related to quality of life after cochlear implantation ${ }^{[7-8]}$. In our study, "parents' perspective questionnaire" which is used in the Nottingham Pediatric Cochlear Implantation Program ${ }^{[9]}$ was conducted on 71 children with CI.

Under the large scale of "quality of life", 11 subscales were investigated which included; decision for implantation ( 7 questions about the process of decision making and the family attitude towards the operation), process of implantation (8 questions asking about the impact of other users meeting, and the impact of the new commitment to the CI rehabilitation program on the routine of the family), positive effect of the implant (5 questions), support (5 questions about the need for more family member support 
after $\mathrm{CI}$ ), communication (5 question searching for the improvement of verbal communication among CI users and family members), self-confidence (5 questions describing the independence of the child after CI surgery), wellbeing and happiness (3 questions), social relationships (6 questions), education (4 questions), services of implant center (6 questions) and quality of life in general (4 questions) (Appendix A).

Table 2 showed no effect of sex of the child on the family decision about CI as well as in other aspects of questionnaire investigated. This means that no predilection for male over female or the opposite was there when the family took the decision of doing or avoiding CI.

When assessing the age of implantation, it was found that children implanted before at age of 4 years and more showed better scores as regards positive effect of CI, self-confidence, and their parents' satisfaction about services of CI centers (Table 3 )

Better perception of effect of implant in the older implanted groups may be attributed to the longer previous period of sensory deprivation, which may explain the obvious and robust perception of CI efficacy. Moreover, as the cutoff age for implantation if 5 years old (insurance regulation), at the time of filling the questionnaire parents perception of better response is obvious as the child is old enough to be observed for auditory responses. Another factor for this conflict is the fact that parents tend to disuse their children;s hearing aids wnever they know they are shifting to CI While better scores regarding communication in the younger implanted group is in favor of the concept of early implantation with its evidence-based relation to neural plasticity ${ }^{[10]}$. As regards self-confidence, older implanted children had better scores that may be due to the ability of parents to judge and the child being experienced a period of withdrawal before implantation $^{[11]}$

Similar significant better scores were observed with advance of age of the children regarding positive effect of implant, communication and self-confidence (Table 5).

Moreover, longer duration of CI yielded statistically significant better score regarding the education percepts. Such observation was in consistent with published studies, measuring hearing performance, reported that effective results were achieved at 18 months after implantation ${ }^{[11]}$. Even though, Allen et al. reported that cochlear implantation improved performance and effective results could be achieved at approximately 3 years after the operation ${ }^{[12]}$.
Significant correlation of all subscale items was found to the total score of quality of life, irrespective to any variable studied. That did not agree with a comparable questionnaire published by Yorgun et $a l .{ }^{[11]}$ who reported that improvement at items of QL questionnaire were correlated to the total score in all items except in the process of decision making. According to Yorgun et al, 93.1\% of parents stated that the perioperative period was very stressful. This observation could not be clarified in our study, which may be attributed to the fact that; QL questionnaires are partially affected by cultures of the population being surveyed that are naturally differ from one country to another. Moreover, CI decision-making depends, to a great extent, on the degree of parents, orientation. Also, it is influenced by the feasibility of implantation process flow determined by the national health care system regulations, which have been eased significantly over the last few years in Egypt, and could have encouraged parents to take the implantation decision and to get into that process eventually. Although being significantly correlated to the total QL score, the subscale "Decision for implantation" was statistically less correlated to total QL score than other subscales. Accordingly, we are still in need for structured workup CI teams, which aims at helping families in this critical period to prevent delay due to hesitation.

The number of questions that were not significant in correlation to the related subscale score was not high, only 5 questions. However, only one of them was not statistically significant correlated to neither the related subscale score nor the total QL score. Thus it can be deleted form the questionnaire without affecting its validity.

As a final statement, using HRQL assessment tools may enable result comparison among clinics which results in a better understanding of the selection criteria for the surgery, and estimation of the needs for habilitating CI children allowing them to develop their maximum potential in all aspects of their daily lives.

\section{CONCLUSION}

Parents' perspective questionnaire used in our study could be used as a valid tool to assess quality of life in children after cochlear implantation. The positive effect of cochlear implants on the quality of life is a fact. The satisfaction of patients is correlated with an increasing duration of the implant and age. However, parents may still have concerns at the preoperative and postoperative periods. So, CI teams need to spend more effort, which aims at helping families in this critical period to prevent delay due to hesitation. 


\section{CONFLICT OF INTEREST}

There are no conflicts of interest.

\section{REFERENCES}

1. Geers AE. Speech, language, and reading skills after early cochlear implantation. Arch Otolaryngol Head Neck Surg. 2004; 130 (5):634-8.

2. Daya H, Ashley A, Gysin C, Papsin BC. Changes in educational placement and speech perception ability after cochlear implantation in children. J Otolaryngol. 2000; 29 (4):224-8.

3. Huber M. Health-related quality of life of Austrian children and adolescents with cochlear implants. Int J Pediatr Otorhinolaryngol. 2005; 69(8):1089-101.

4. Huttunen K, Rimmanen S, Vikman S, Virokannas $\mathrm{N}$, Sorri M, Archbold S, et al. Parents' views on the quality of life of their children 2-3 years after cochlear implantation. Int J Pediatr Otorhinolaryngol. 2009; 73(12):1786-94

5. Patrick D, Edwards C, Skalicky M, Schick B, Topolski D, Kushalnagar P and Sie, K. Validation of a qualityof-life measure for deaf or hard of hearing youth. Otolaryngology--Head and Neck Surgery. 2011; $70: 166-174$
6. The WHOQOL Group. The World Health Organization Quality of Life Assessment(WHOQOL). Development and psychometric properties. Soc Sci Med 1998;46: 1569-1585.

7. Schorr EA, Roth FP, Fox NA. Quality of life of children with cochlear implants: relationship between perceived benefit and problems and perception of speech and emotional sounds. J Speech Language Hear Res. 2009; 141-52.

8. Warner-Czyz AD, Loy B, Roland PS, Tong L. Tobey Parent versus child assessment of quality of life in children using cochlear implants. Int $\mathrm{J}$ Pediatr Otorhinolaryngol. 2009; 1423-9.

9. Tracey, $\mathrm{H}$ and David, $\mathrm{W}$ : Pediatric cochlear implantation: the view of parents. International Journal of Audiology, 2009; 44(7): 400-407.

10. Geers AE, Nicholas JG, Sedey AL. Language skills of children with early cochlear implantation. Ear Hear. 2003; 24:46-58.

11. Yorgun M, Sürmelioğlu Ö, Tuncer Ü, Tarkan Ö, Özdemir S, Çekiç E et al. Quality of Life in Pediatric Cochlear Implantations. J Int Adv Otol. 2015; 11(3): 218-21.

12. Allen C, Nikolopoulos TP, O’Donoghue GM. Speech intelligibility in children after cochlear implantation. Am J Otol.1998; 19: 742-6. 


\section{Appendix:}

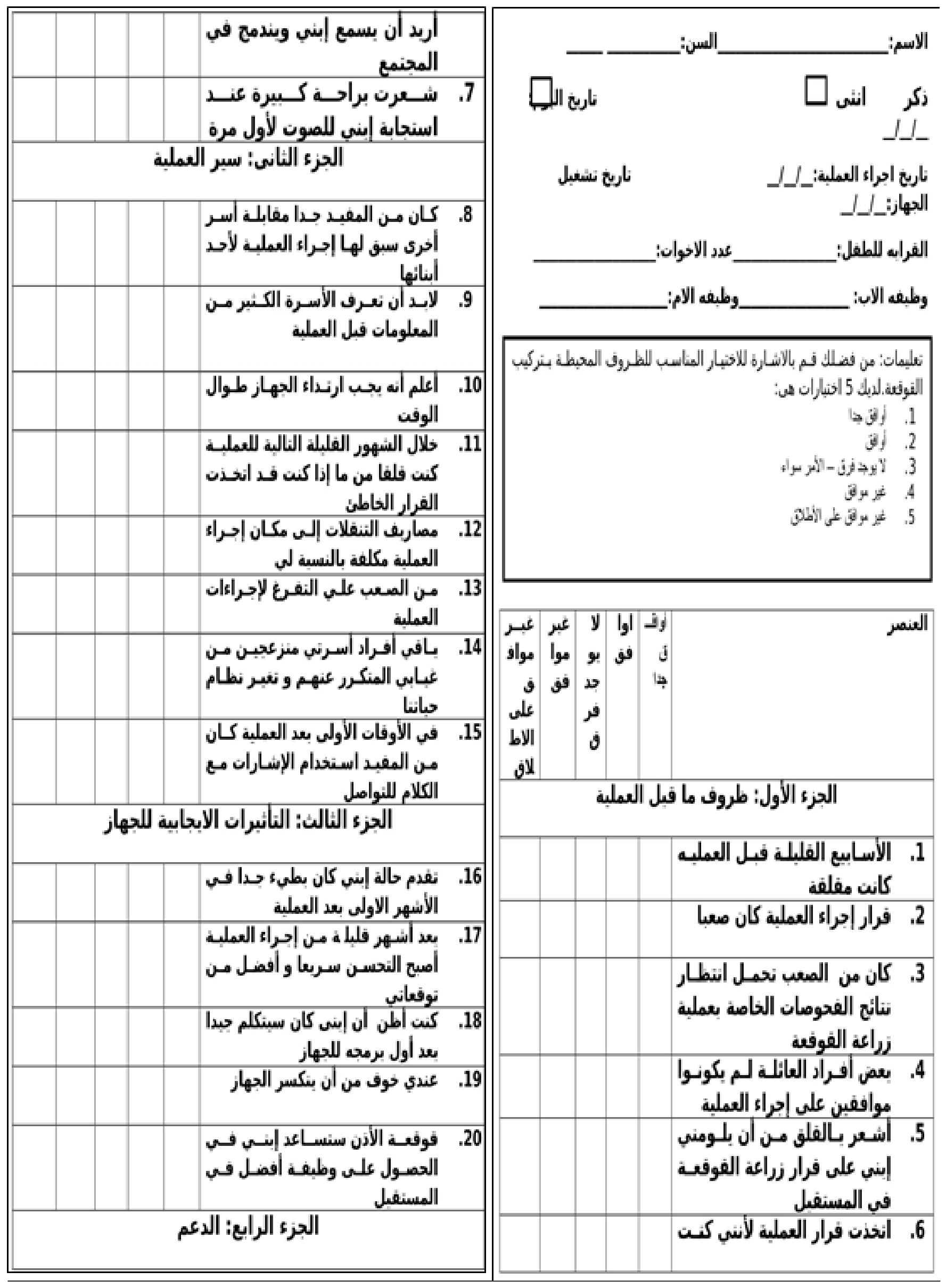




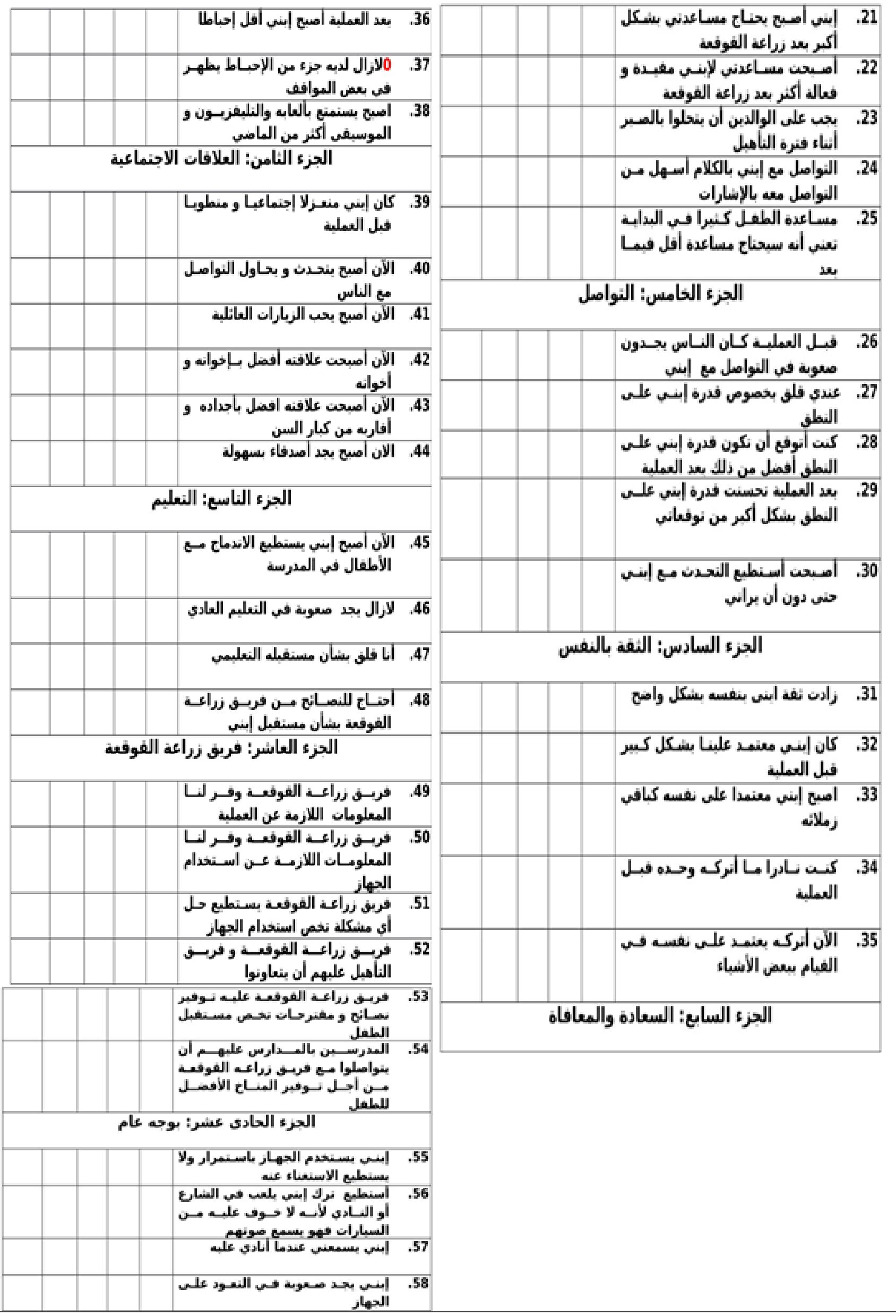

